\title{
IMPACT OF A COMPRESSIVE STRESS ON WATER SORPTION AND DIFFUSION IN IONOMER MEMBRANES FOR FUEL CELLS.
}

\section{A ${ }^{1}$ H-NMR STUDY IN VAPOR-EQUILIBRATED NAFION®.}

Assma El Kaddouri ${ }^{1,2,}{ }^{*}$, Jean-Christophe Perrin ${ }^{1,2}$, Thibaut Colinart ${ }^{3}$, Christian Moyne ${ }^{1,2}$, Sébastien Leclerc $^{1,2}$, Laouès Guendouz ${ }^{4}$, Olivier Lottin ${ }^{1,2}$

\author{
${ }^{1}$ Université de Lorraine, LEMTA, UMR 7563, Vandouvre-lès-Nancy, F-54500, France \\ ${ }^{2}$ CNRS, LEMTA, UMR 7563, Vandouvre-lès-Nancy, F-54500, France \\ ${ }^{3}$ Univ. Bretagne Sud, FRE CNRS 3744, IRDL, F-56100 Lorient, France \\ ${ }^{4}$ Institut Jean-Lamour, UMR 7198, CNRS, Université de Lorraine, Vandouvre-lès-Nancy, F- 54500, France
}

KEYWORDS: PEM membranes, Nafion ${ }^{\circledR}$, water self-diffusion, pulsed-field gradient NMR, water sorption, clamping pressure, durability, mechanical stress, compression

\begin{abstract}
The electrolyte membrane is exposed to high compression loads when operating in a proton exchange membrane fuel cell (PEMFC). It was reported in the literature that compression impacts the membrane properties when immersed in liquid water but little is known about the quantitative effects of stress on water sorption and its dynamical properties when the membrane is at equilibrium with a humid gas. In this work, we investigated the influence of a static normal stress on the properties of Nafion® by pulsed field gradient NMR (PFGNMR) with a NMR compatible compression device. The results demonstrated a reduction in water content due to compression at high relative humidity $(\geq 90 \% \mathrm{RH})$ and much more moderate effects at low hydration $(\leq 85 \% \mathrm{RH})$. The changes observed on the diffusion properties are more pronounced and related to both water loss and a reversible modification of the membrane structure effective at the micrometric scale.

* corresponding author
\end{abstract}




\section{Introduction}

Many challenges related to the increase of the reliability and lifetime of proton exchange membrane fuel cells (PEMFCs) are still present despite the worldwide commercial level that they have already reached. Literature studies performed during the last decade pointed out lifetime issues resulting from component failures, especially the proton exchange membrane. The most extensively used membrane in PEMFCs is the perflurosulfonic acid long side chain (PFSA LSC) Nafion® (E.I. Dupont de Nemours and Co.). This copolymer is composed of a polytetrafluoroethylene (PTFE) backbone and perfluorovinyl ether pendant side chains terminated by sulfonic ionic groups $\left(\mathrm{SO}_{3}{ }^{-}\right)$. The large body of literature indicates that membrane failures result mainly from chemical ${ }^{1-6}$ or/and mechanical ${ }^{4,6}$ degradations.

\section{Effect of mechanical stress on membrane properties}

During fuel cell operation a clamping pressure in the range $[0.5-3 \mathrm{MPa}]$ is applied to the MEA to ensure a minimal contact resistance between the components and avoid fuel leakage ${ }^{7,8}$. A few studies ${ }^{6-9}$ outline that the value of the clamping pressure needs to be optimized to ensure a low contact resistance between the bipolar plates and the gas diffusion layers. This permanent compressive stress is highly inhomogeneous throughout the cell due to the repetitive channel/rib pattern of the bipolar plates. Under the land of the bipolar plates, the membrane undergoes timedependent deformations which can lead to permanent membrane thinning and might influence its structural organization and therefore its sorption capacity and transport properties. Therefore, several studies have focused on the impact of a compressive stress on the membrane sorption and transport properties.

\section{Experimental approach}

Few experimental studies have been performed to measure the water content and the proton conductivity of Nafion ${ }^{\circledR}$ membranes under a compressive stress. Experimental data have been reported regarding the water content under compression using neutron imaging ${ }^{10,11}$, small-angle $\mathrm{X}$ - 
ray scattering (SAXS) ${ }^{12,13}$ or confocal $\mu$-Raman spectroscopy ${ }^{14}$. Kusoglu et al. ${ }^{10}$, measured with neutron imaging a decrease of 10 to $15 \%$ of the water content in a liquid equilibrated membrane for a compressive stress ranging from 2 to $4 \mathrm{MPa}$. This impact of compression on the water content was also pointed out by Otmani ${ }^{13}$ and Sutor et al. ${ }^{14}$ and correlated with a significant thickness reduction ${ }^{12,15,16}$. In Otmani's study ${ }^{13}$ a specific tightening device which mimics the geometry of the flow field was designed and used to measure the behavior of the water content under the ribs and channels. The authors carried out SAXS experiments to follow the so-called ionomer peak, whose position is related to the spacing between hydrophilic domains (d-spacing). The results under the ribs mainly highlight a decrease of the spacing in the thickness direction when a compressive stress ranging from 1 to $15 \mathrm{MPa}$ is applied. Under $1 \mathrm{MPa}$ the decrease is identical in the in-plane and through-plane directions while for higher applied stress an anisotropic behavior appears. With the same tightening device, Sutor et al. ${ }^{14}$ investigated the local water content change under ribs and channel using $\mu$-Raman. The Raman spectra were collected along the thickness at a constant depth $(25 \mu \mathrm{m})$ inside Nafion ${ }^{\circledR}$ NRE212 and Aquivion ${ }^{\circledR}$ E79 membranes. The results showed a significant and progressive decrease of the water content with the applied compressive stress. At low stress (1 MPa) both Aquivion ${ }^{\circledR}$ and Nafion ${ }^{\circledR}$ exhibited a significant water loss under the ribs and under the channels $(5-22 \%)$ compared to the uncompressed references. Above $1 \mathrm{MPa}$ the water loss seemed to remain constant under the channel. These results have been interpreted using the structural model developed by Rubatat et al. ${ }^{17}$ which describes the membrane's structure as based on bundles of more or less oriented fibrils which are composed of elongated polymeric aggregates surrounded by the ionic charges. The results showed that the compressive stress creates an alignment of the bundles under the ribs in the direction perpendicular to the applied stress. Kusoglu et al. ${ }^{12}$ performed a SAXS analysis on Nafion ${ }^{\circledR}$ NR212 under compressive loads in liquid water in the face-on (in-plane) and in the edge-on (thickness) directions. The results showed that the spacing between adjacent water channels decreases with the applied stress in the in-plane direction and 
decreases in the thickness (i.e. the compressive direction). The different behaviors observed in the nanostructure between the in-plane and the though-plane directions in the liquid equilibrated Nafion ${ }^{\circledR}$ suggest that compressive stress creates nanoscale anisotropy. In order to understand the behavior in vapor-equilibrated samples, the same SAXS experiments were carried out in the inplane configuration in controlled humidity conditions. The evolution of the d-spacing in the membrane plane showed that compression induces a similar increase of the water channel spacing in membranes equilibrated at high humidity $(\geq 94 \% \mathrm{RH})$ but with a much lower amplitude compared to the liquid equilibrated samples. At lower relative humidity $(\leq 84 \% \mathrm{RH})$, the results suggest that compression stress does not cause significant change in the hydrophilic domain spacing. Unfortunately, no conclusion could be made regarding the emergence of a structural anisotropy in vapor-equilibrated compressed membranes since no result of the evolution of the dspacing in the thickness direction was reported. The authors outlined that the compression stress $(0-$ $8 \mathrm{MPa}$ ) at low and high $\mathrm{RH}$ had no marked effect on through plane conductivity. Nevertheless, they detected an anisotropy of the proton conductivity between in-plane and through-plane directions when the membrane was compressed.

\section{Modeling approach}

In parallel to the previous experimental investigations, a large number of models ${ }^{10,18-24}$ have been proposed to explain the swelling behavior of Nafion ${ }^{\circledR}$ membrane under compression. For instance, Kusoglu et al. ${ }^{12}$ investigated the effect of compression on water content and proposed a predictive model of conductivity change. Their model exhibited a decrease of both water content and the mean distance between swollen-water-domains in the membrane as a function of stress. Moreover, the model predicted a decrease of the conductivity in the plane with increasing stress with more pronounced effects at high RH. More recently, Colinart et al. ${ }^{25}$ proposed a model which accounts for the electrostatic interactions at the local scale to describe the swelling behavior of Nafion ${ }^{\circledR}$ membrane undergoing compressive stress. The model was based on a modified Biot poroelasticity 
theory accounting for the electrostatic interactions at the microscale that was upscaled using an asymptotic homogenization procedure. Knowing the elastic modulus of the membrane, this model enabled the prediction of water content in a membrane at equilibrium with liquid water under different type of external compressive stress (uniform, uniaxial compression or under oedometer test).

\section{Objectives of the present work}

While it was reported in the literature that compression influences the sorption capacity of a proton exchange membrane immersed in liquid water, very little is known about the effects of the stress on the water sorption and its dynamical properties when the membrane is at equilibrium with a humid gas. This probably comes from experimental obstacles which make difficult the determination of the water content and the simultaneous measurement of its transport properties, either water diffusion or proton conductivity.

In this work, we developed a specific NMR compatible compression setup in order to quantify the evolution of the water content in a PFSA membrane exposed to a variable normal stress and equilibrated in a controlled relative humidity environment. We used pulsed field gradient NMR (PFGNMR) to measure the water self-diffusion coefficient along any spatial direction and gain access to the dynamical properties of the adsorbed water in the compressed structure of the membrane. This study follows our previous work (see reference ${ }^{26}$ ) on the measurement of water diffusion anisotropy in a Nafion ${ }^{\circledR}$ membrane under traction using the same technique. As pointed out by Klein et al. ${ }^{26}$, one of the main advantage of PFGNMR compared to conductivity measurements is that it is insensitive to interface effects and membrane thickness variations as it is a non-contact method. We present data on the evolution of both water content and water diffusion in the stressed membrane in the range $[0-12 \mathrm{MPa}]$ and $[15-98 \% \mathrm{RH}]$. The water diffusion properties were probed along the three orthogonal axes in order to detect stress induced anisotropic effects. 
The water content data were compared to the predictions of the model developed by Colinart et al. 25.

\section{Experimental}

\section{Sample preparation}

Extruded Nafion ${ }^{\circledR}$ N1110 membrane $(1100 \mathrm{~g} /$ mole equivalent weight and $254 \mu \mathrm{m}$ nominal thickness) were purchased in acid $\left(\mathrm{H}^{+}\right)$form from Ion Power, Inc. All samples were pre-treated following a standard protocol ${ }^{27}$ : the received membranes were first pre-cleaned by boiling in 3 wt.\% oxygen peroxide to eliminate organic residues. They were then rinsed with demineralized water at room temperature. To guarantee a complete acidification, the samples were soaked in aqueous $10 \mathrm{M}$ nitric acid $\left(\mathrm{HNO}_{3}\right)$ at room temperature during $30 \mathrm{~min}$ and rinsed with demineralized water. Finally, the membranes were boiled 1 hour in aqueous $1 \mathrm{M}$ sulfuric acid $\left(\mathrm{H}_{2} \mathrm{SO}_{4}\right)$ and then 1 hour in demineralized water. After this cleaning / acidification protocol, $5 \mathrm{~mm}$ diameter membrane discs were cut out using a die and soaked in a ethylenediaminetetraacetic acid (EDTA) solution at room temperature to remove any remaining paramagnetic contaminants (mostly $\mathrm{Cu}^{2+}$ and $\mathrm{Mg}^{2+}$ ). These impurities can significantly shorten the NMR spin-spin $\left(T_{2}\right)$ and spin-lattice $\left(T_{1}\right)$ relaxation times of the water protons due to magnetic interactions between the proton nuclear magnetic moments of the water protons and the unpaired electrons of the cations ${ }^{28}$. Finally samples were dried at $60^{\circ} \mathrm{C}$ during 24 hours.

\section{NMR hardware and compression setup}

A 2D NMR coil and a pneumatic compression cell were specifically designed for the NMR characterization of vapor-equilibrated membranes under compression.

\section{NMR coil}

Surface NMR coils are commonly used in the field of medical histology ${ }^{29}$. Thanks to their high sensitivity when placed immediately above or below a thin film they have also demonstrated their 
ability in measuring high resolution water profiles through $N a f i o n{ }^{\circledR}{ }^{30-32}$ or the evolution of the water diffusion properties when a Nafion ${ }^{\circledR}$ membrane is exposed to a tensile stress ${ }^{26,33,34}$. The $2 \mathrm{D}$ coil developed for the present study is a circular $10 \mathrm{~mm}$ loop of copper wire (diameter $=0.6$ $\mathrm{mm}$ ) covered with $6.6 \mu \mathrm{m}$ silver coating (Figure 1(d)). The coil was used for Radio Frequency excitation and for signal reception. Tuning and matching were achieved by a symmetrical capacitive circuit.

\section{Compression cell}

The body (36 x $44 \mathrm{~mm}$ ) of the compression cell (Figure 1(a) and (b)) was composed of a chamber, a mobile piston, a cover and a chamber cap made out of polyetheretherketone (PEEK). The $5 \mathrm{~mm}$ diameter membrane sample was mounted between two porous quartz discs (nominal pore size: 16$40 \mu \mathrm{m})$ to evacuate water when the pneumatic pressure was applied. Brass screws and nuts were used together with polymethylmethacrylate (PMMA) spacers to tighten the assembly. The NMR coil was positioned around the bottom porous disc below the membrane plane. To maintain constant and homogeneous hygrometric conditions in the membrane environment, a flexible hose (6 mm ID) was placed close to the membrane between the two spacers and brought humid air at a fixed relative humidity $(15 \%<\mathrm{RH}<98 \%)$ and a flow rate of $\sim 1.5 \mathrm{NL} / \mathrm{min}$. The real time measurement of the air relative humidity with a capacitive sensor (Vaisala) allowed the determination of RH with an accuracy of 1 to $2 \%$, depending of the RH value. The uniaxial compressive stress was applied normal to the membrane by pushing the mobile piston with compressed nitrogen at an absolute pressure $0<\mathrm{P}<12$ bars. A calibration of the true compressive stress as a function of the applied nitrogen pressure was performed and is presented in the Supporting Information. Multiple trials were achieved in order to provide a standard deviation of the compressive stresses (plotted as error bars in all the figures presenting compressive stress). All the NMR experiments were carried out at a temperature of $24 \pm 2{ }^{\circ} \mathrm{C}$. 


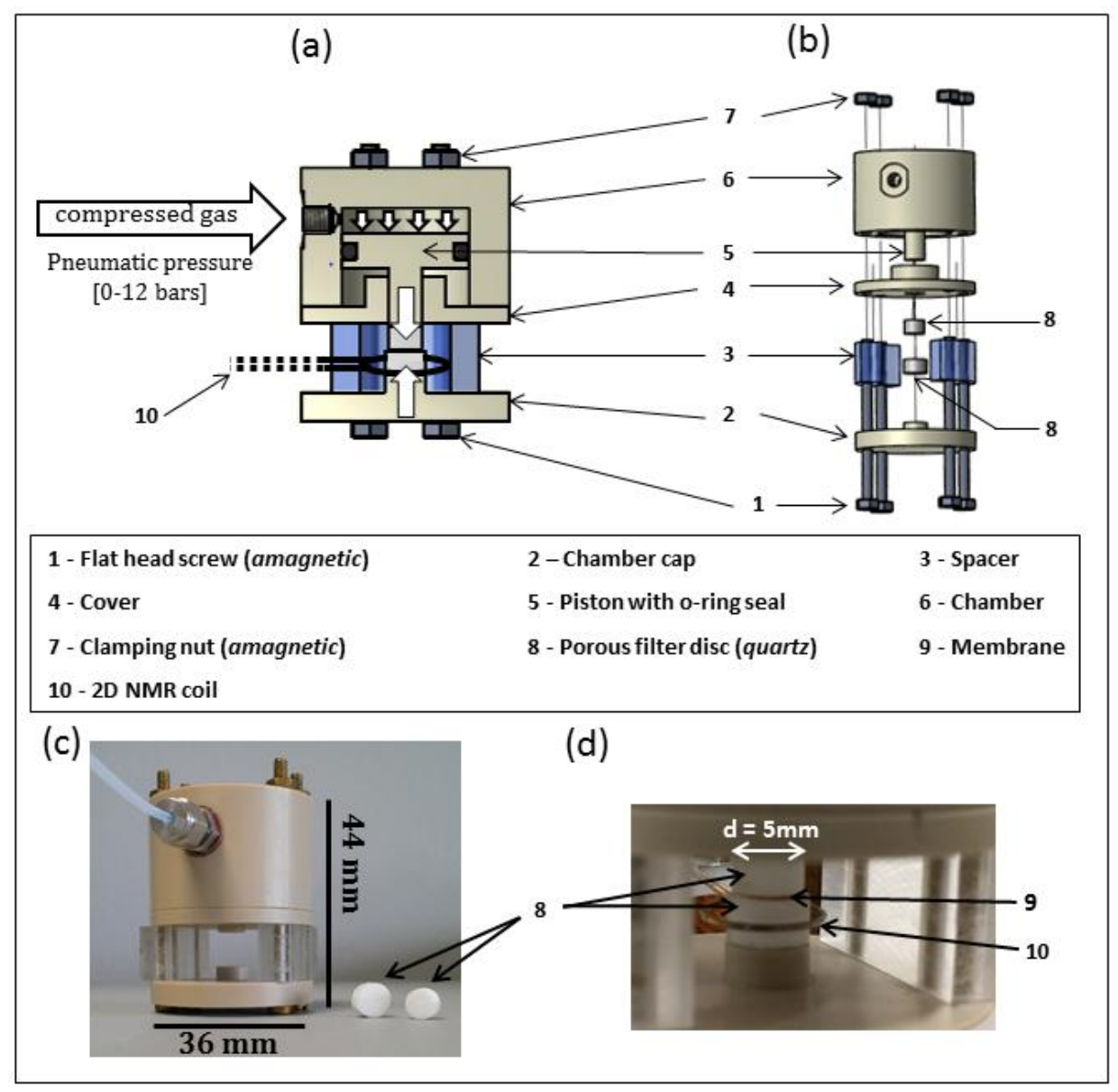

Figure 1. Schematics and pictures of the compression NMR setup: (a) operation scheme with the 2D NMR coil (b) exploded view (c) picture of the compression setup and the two porous discs, (d) picture of the compressive zone with the porous discs, the membrane $(\mathrm{d}=5 \mathrm{~mm})$ and the $2 \mathrm{D}$ NMR coil.

\section{NMR experiments}

The NMR experiments were performed on a horizontal Bruker Avance BioSpec 24/40 operating at a proton Larmor frequency of $100.36 \mathrm{MHz}$ and equipped with a water cooled three-axis gradient unit providing a maximum magnetic field gradient strength $(\boldsymbol{g})$ of $20 \mathrm{G} / \mathrm{cm}$. The compression cell was placed in the $20 \mathrm{~cm}$ aperture of the gradient coil and aligned such that the plane of the membrane lies in the $\boldsymbol{x}-\mathbf{z}$ plane of the reference axes of the spectrometer, where $\mathbf{z}$ is defined by the direction of the static magnetic field $\overrightarrow{\boldsymbol{B}_{\mathbf{0}}}$ (Figure 2). Changing the orientation of the magnetic field gradients with respect to the sample plane allows the measurement of the water self-diffusion coefficient in the plane $\left(\boldsymbol{D}_{\boldsymbol{x}}, \boldsymbol{D}_{z}\right)$ and through the plane $\left(\boldsymbol{D}_{\boldsymbol{y}}\right)$ of the membrane. 


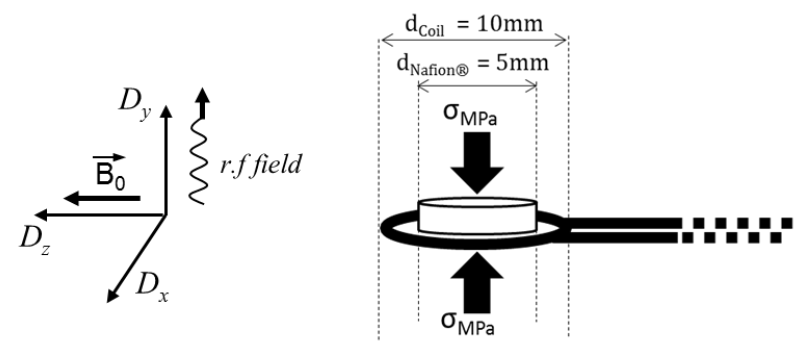

Figure 2. Dimensions of the NMR probe and the membrane sample and relative orientation of the membrane plane with respect to the reference axes of the NMR spectrometer.

For proton spectra, $5.2 \mu \mathrm{s}(\boldsymbol{\pi} / \mathbf{2})$ pulses, 16 accumulations and a recycle delay of $1.2 \mathrm{~s}$ were used. Proton spin-spin $\left(\boldsymbol{T}_{\mathbf{2}}\right)$ relaxation times were measured using a standard Car-Purcell-Meiboom-Gill (CPMG) sequence with an echo spacing of $0.8 \mathrm{~ms}, 64$ accumulations, and a recycle delay of $1.2 \mathrm{~s}$. The water self-diffusion experiments were carried out using a stimulated spin-echo sequence (PGSTE) with unipolar gradients. The duration of the magnetic gradient pulse was set in the range $10<\delta<14 \mathrm{~ms}$ and the diffusion time in the range $50<\Delta<150 \mathrm{~ms}$, depending on the hydration of the membrane. 128 scans were accumulated with a recycle delay ranging from 1 to $2 \mathrm{~s}\left(>5 \mathrm{x} \boldsymbol{T}_{\mathbf{1}}\right.$, whatever the water content). The water self-diffusion $\boldsymbol{D}$ was calculated from a plot of the signal attenuation $\boldsymbol{S} / \boldsymbol{S}_{\mathbf{0}}$ versus the magnitude of the gradient $\boldsymbol{g}$ using the Stejskal-Tanner equation (Equation 1):

$$
S=S_{0} e^{-\left[D \gamma^{2} g^{2} \delta^{2}\left(\Delta-\frac{\delta}{3}\right)\right]}
$$

Equation 1

where $\boldsymbol{S}$ and $\boldsymbol{S}_{\mathbf{0}}$ are the signal intensities at $\boldsymbol{g}$ and $\boldsymbol{g}=\mathbf{0}$, respectively and $\boldsymbol{\gamma}\left(\boldsymbol{r a d} . \boldsymbol{s}^{-\mathbf{1}} . \boldsymbol{T}^{-\mathbf{1}}\right)$ is the gyromagnetic ratio of the hydrogen nucleus. The length scale $\boldsymbol{l}$ probed by the water molecules in the direction of the applied magnetic field gradient during the diffusion experiments is given by $l=(2 D \Delta)^{1 / 2}$ and ranges approximately from 2 to $5 \mu \mathrm{m}$. This scale is much larger than all the known structural elements of Nafion ${ }^{\circledR}$ membranes such that the value of the self-diffusion coefficient reflects the tortuosity of the hydrophilic network. A validation test has been performed on liquid water to check that the metallic parts of the cell (brass screws and stainless steel fittings) 
did not introduce artifacts during the PFGNMR experiments. The corresponding measurements are presented in the Supporting Information.

\section{Results}

\section{${ }^{1}$ H-NMR parameters in a Nafion ${ }^{\circledR}$ membrane under a uniaxial compressive stress}

Figure 3 presents the ${ }^{1} \mathrm{H}$ NMR spectra of Nafion ${ }^{\circledR}$ N1110 under stress in the range [0-11 MPa]. The membrane was equilibrated at 61\% RH (Figure 3a)) and 95\% RH (Figure 3b)). The ${ }^{1} \mathrm{H}$ resonance line measured before applying the stress was broad $(\sim 50 \mathrm{~Hz}$ at $61 \% \mathrm{RH})$ as a result of the poor magnetic field homogeneity in the vicinity of the membrane sample due to the presence of the metallic parts of the cell (fitting, screws). When a stress was applied, the resonance lines translated to higher values of the chemical shift and the signal areas (integrals of the lines) decreased (mostly seen at $95 \% \mathrm{RH})$. The chemical shift and the signal area $\left(\boldsymbol{A}_{\boldsymbol{N} M R}\right)$ are plotted on Figure $\left.4 \mathrm{a}\right)$ and $\mathrm{b}$ ) respectively as a function of the applied stress. In an unstressed membrane, the ${ }^{1} \mathrm{H}$ chemical shift is known to be linearly dependent of the inverse of the amount of water adsorbed closed to the sulfonic acid groups ${ }^{1,35,36}$. If the chemical shift were only dependent on the water content, then this parameter could be used to follow the evolution of the amount of adsorbed water in the sample under stress with the help of a calibration curve. The chemical shift, however, is dependent on the local electron density experienced by the water protons and may thus vary with the applied stress because of the deformation of the polymer matrix. We show in the Supplementary Information that the slope of the calibration curve of the chemical shift with respect to the inverse water content changed when the membrane was under a compressive stress. This result prevented us to use the chemical shift as a marker of the absolute water content in a stressed membrane. 

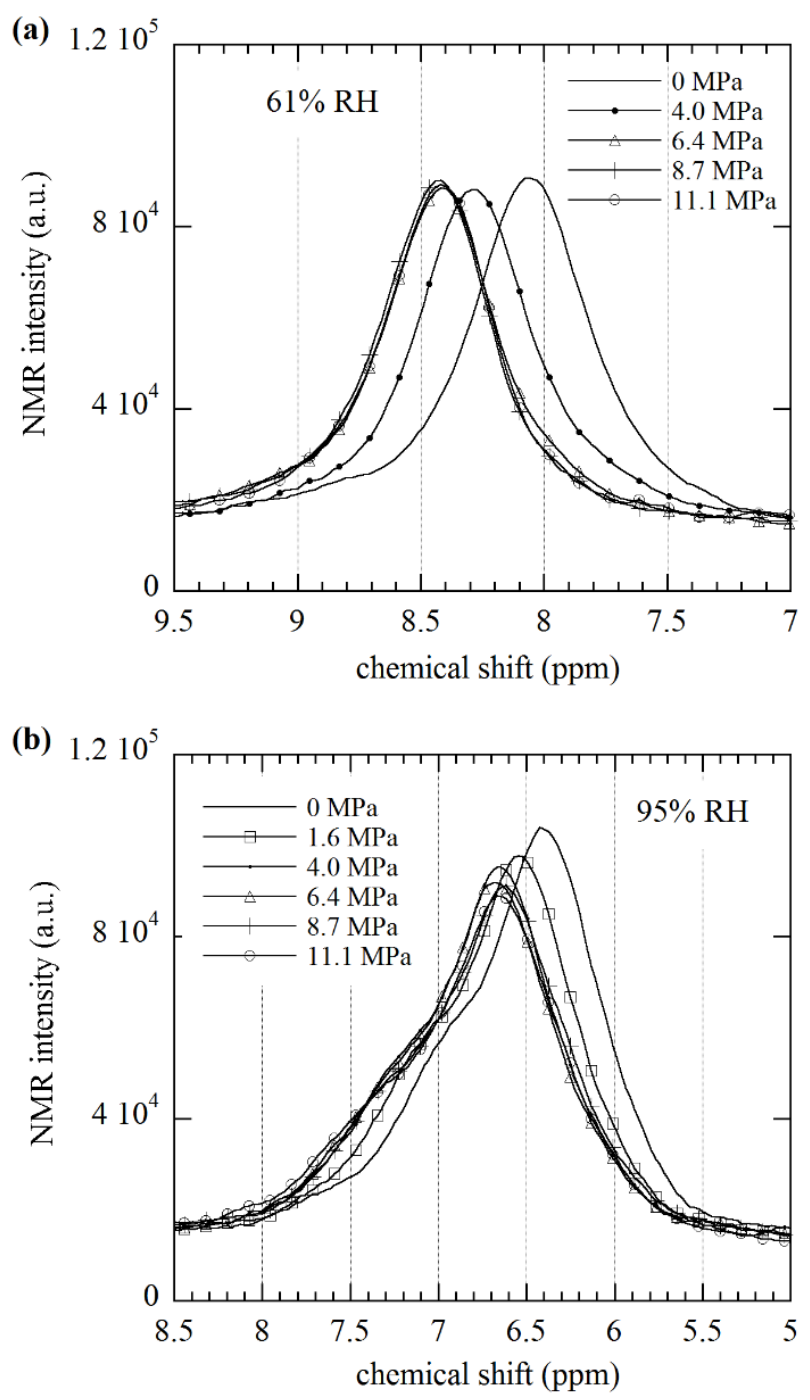

Figure 3. ${ }^{1} \mathrm{H}$ NMR spectra of a vapor-equilibrated Nafion ${ }^{\circledR}$ membrane under a variable compressive stress. (a) $61 \% \mathrm{RH}$ and (b) $95 \% \mathrm{RH}$.

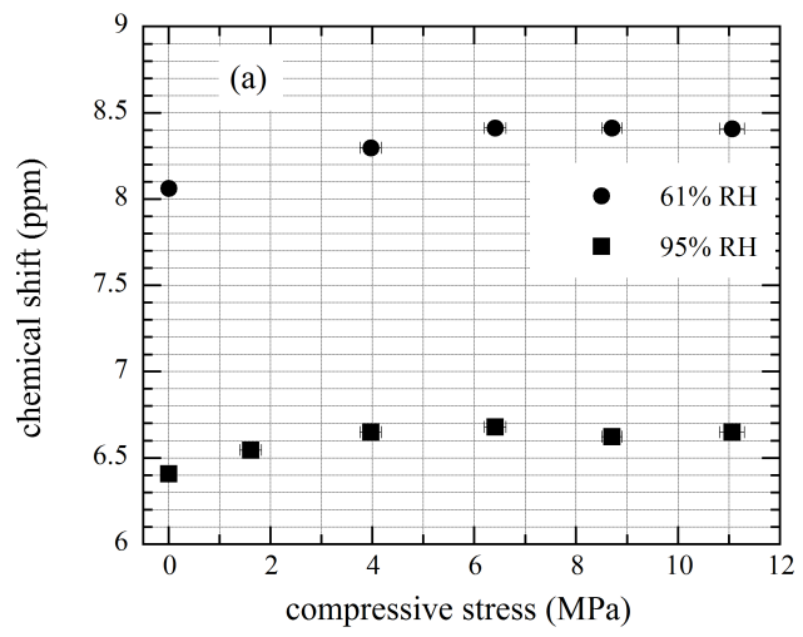




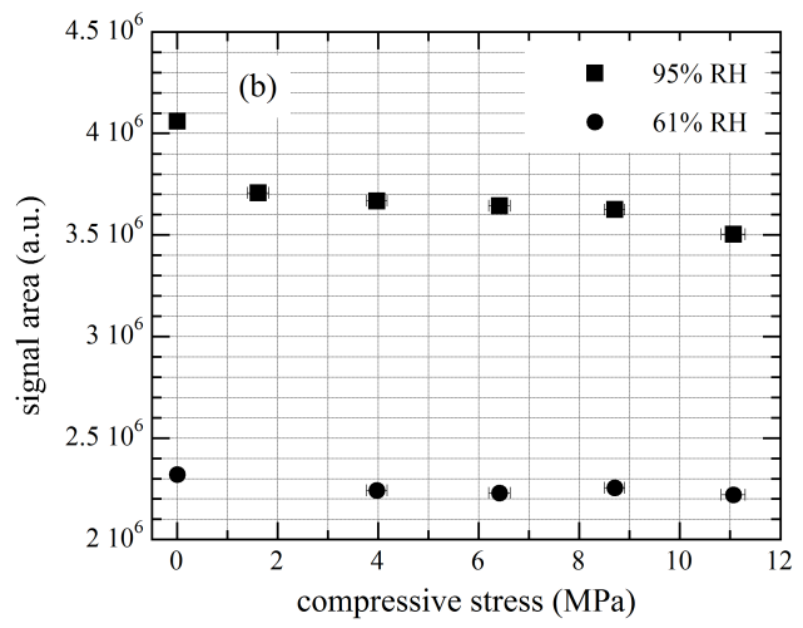

Figure 4. (a) Chemical shift and (b) NMR signal area as a function of the applied stress in N1110 membranes equilibrated at $61 \% \mathrm{RH}$ and $95 \% \mathrm{RH}$.

The integral of the NMR line can also be used as an indicator of the water content. Since the membrane sample $(5 \mathrm{~mm}$ in diameter) is entirely inside the excitation volume of the $2 \mathrm{D}$ coil the signal area corresponds to all the protons present in the sample and its variations can be used to follow the effects of stress on the water content. With the help of a calibration curve based on equilibrium sorption measurements (see next sections) it is fairly easy to extract a very reliable correspondence between $\boldsymbol{A}_{\boldsymbol{N} \boldsymbol{M} \boldsymbol{R}}$ and the hydration parameter $\lambda$.

Finally, the evolution of the water transverse relaxation time $\boldsymbol{T}_{\mathbf{2}}$ represents another probe of the water content as it strongly increases with the amount of adsorbed water in the polymer matrix. This reflects the acceleration of the water dynamics as the water molecules are less and less bound to the hydrophilic sites ${ }^{37,38}$. As observed in Figure $5 \boldsymbol{T}_{\mathbf{2}}$ decreased with the applied stress for the two samples, which demonstrates a decrease of the water content. The water loss seems to be more pronounced at high relative humidity $\left(\boldsymbol{T}_{2}\right.$ decreases from $107 \pm 1 \mathrm{~ms}$ to $82 \pm 1 \mathrm{~ms}$ when the stress increased from 0 to $11.1 \mathrm{MPa}$ at $95 \% \mathrm{RH}$ and from $60 \pm 1.5 \mathrm{~ms}$ to $53 \pm 1.5 \mathrm{~ms}$ at $61 \% \mathrm{RH})$. The $\boldsymbol{T}_{2}$ values, however, are also very sensitive to the presence of impurities in the membrane and are dependent on the membrane history. We observed marked differences in the $\boldsymbol{T}_{\mathbf{2}}$-water content relationship between two different membrane samples that originated from the same batch and were washed using the same protocol. The relative variations of $\boldsymbol{T}_{\mathbf{2}}$ with the applied stress are thus 
difficult to link to the absolute water loss. Like the chemical shift, we note that $\boldsymbol{T}_{\mathbf{2}}$ may be influenced by the local water environment in the membrane. The possible evolution of the local pore structure with the applied stress can influence the water relaxation by changing the watermatrix interactions. For these reasons, the water transverse relaxation time is not a relevant parameter to characterize the water content of a compressed membrane.

As a consequence, among the three stress-sensitive NMR parameters (chemical shift, signal area and $\left.\boldsymbol{T}_{2}\right)$, we chose to follow only the signal area $\left(\boldsymbol{A}_{N M R}\right)$ to quantify the membrane water content.

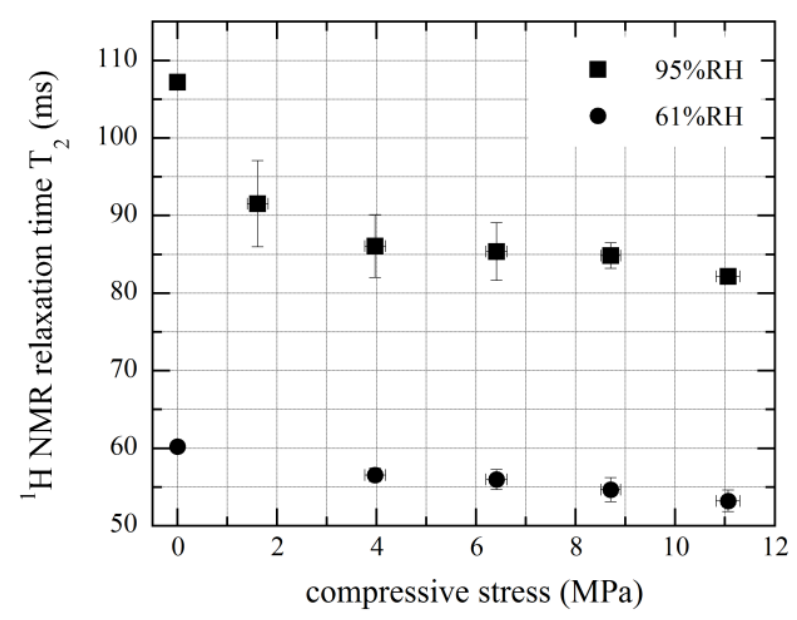

Figure 5. Effect of compression on the proton NMR transverse relaxation time $\left(T_{2}\right)$ of water in Nafion ${ }^{\circledR}$ N1110 equilibrated at $61 \%$ and $95 \%$ RH.

\section{Equilibration times}

Figure 6(a) presents the time evolution of $\boldsymbol{A}_{\boldsymbol{N M R}}$ measured in an unstressed membrane initially vapor-equilibrated at $30 \% \mathrm{RH}$ after a step change of the air humidity from 30 to $67 \% \mathrm{RH}$. The initial time was taken when the humidity value was changed and several NMR spectra were recorded in a period of 90 minutes. The experiments show a fast initial increase of the water content during the first five minutes. It then took fifteen more minutes to reach a stability zone with quasiconstant water content. After 90 minutes, the compressive stress was set to $11.1 \mathrm{MPa}$ and the NMR spectra were recorded for 90 additional minutes (the air humidity was maintained at $67 \% \mathrm{RH}$ ). The 
data (Figure 6 (b)) show that most of the water loss happened in the first 20 minutes and that equilibrium is reached afterwards.

In the next sections, the reported values of the water content and water self-diffusion coefficient were measured at equilibrium. To make sure that equilibrium was reached, the data were recorded at least 60 minutes after a change in the air relative humidity or in the applied stress. The uncertainty of each measurement was evaluated by calculating the mean value and standard deviation of the last four data points signal area or $\mathrm{T}_{2}$ ).
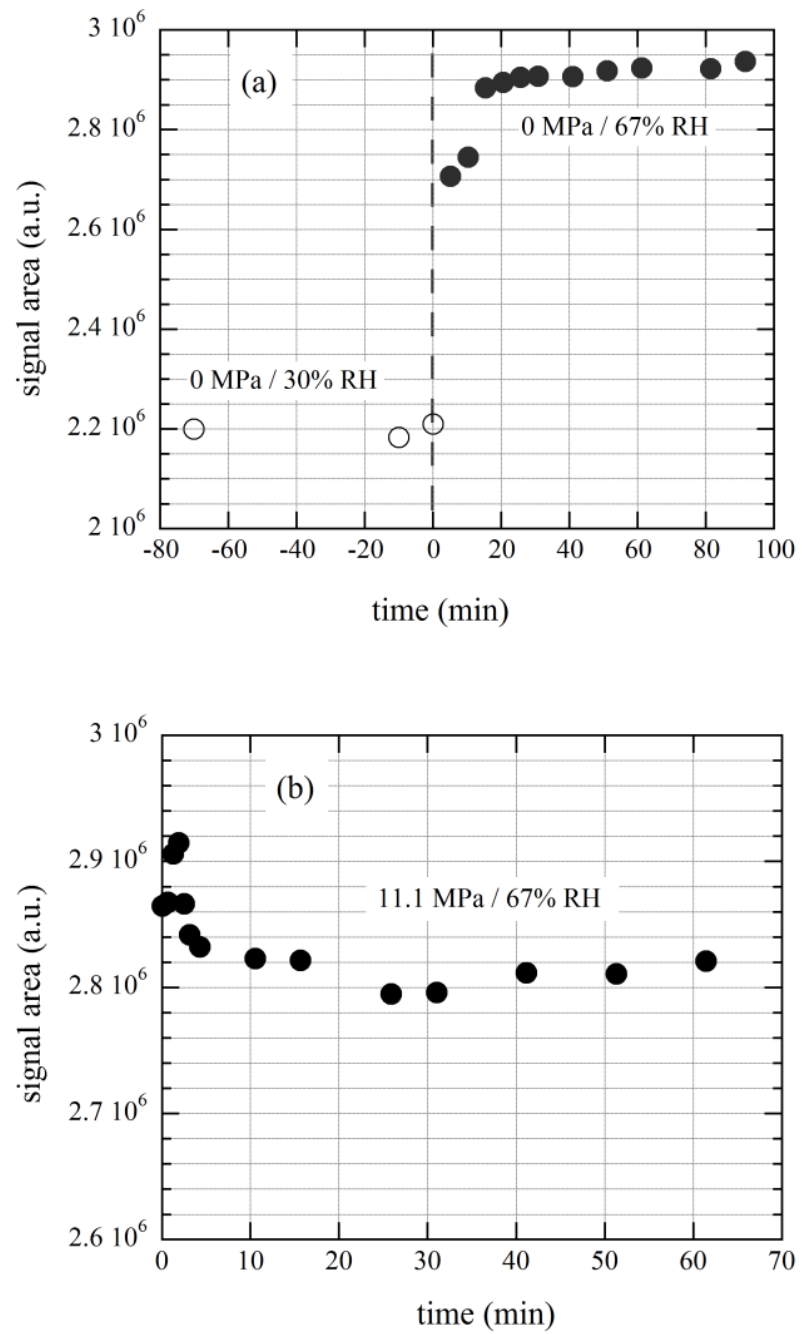

Figure 6. Time-evolution of the ${ }^{1} \mathrm{H}-\mathrm{NMR}$ signal area $A_{N M R}$ : (a) unstressed membrane initially equilibrated at $30 \% \mathrm{RH}$ after a step change of the air relative humidity from 30 to $67 \% \mathrm{RH}$ at $t=0$. (b) Initially unstressed membrane equilibrated at $67 \% \mathrm{RH}$ after a step change of the compressive stress from 0 to 11.1 MPa at $\mathrm{t}=0$. 


\section{Water sorption in a compressed $(8.7 \mathrm{MPa})$ Nafion® membrane}

The water sorption isotherm of Nafion ${ }^{\circledR} \mathrm{N} 1110$ was measured at $24^{\circ} \mathrm{C}$ in the unstressed membrane and in a membrane subjected to a compression stress of $8.7 \mathrm{MPa}$. The reference curve was first measured by exposing the membrane to 1.5 to 2 hours long successive humidity steps. The signal area $\boldsymbol{A}_{\boldsymbol{N M R}}(\mathbf{R H})$ was measured at equilibrium for each $\mathrm{RH}$ and converted to water content $\lambda=$ $\left[\mathrm{H}_{2} \mathrm{O}\right] /\left[\mathrm{SO}_{3} \mathrm{H}\right]$ using a scaling factor corresponding to the water content measured at $50 \% \mathrm{RH}$ on a microbalance at the same temperature $\lambda(\mathbf{5 0} \%)=\mathbf{3 . 9 8}$ :

$$
\frac{\lambda(\boldsymbol{R H})}{\lambda(50 \%)}=\frac{A_{N M R}(\mathbf{R H})-A_{N M R}(0)}{A_{N M R}(50 \%)-A_{N M R}(0)}
$$

The membrane was then exposed again to $0 \% \mathrm{RH}$ and the stress was applied to the dry membrane (the dew point of the dry air was below $-60^{\circ} \mathrm{C}$ ). The sorption isotherm of the compressed membrane was measured using the same protocol as for the unconstrained one. The real-time measurement of the RH during the NMR experiments allowed the determination ofthe mean value and standard deviation of each RH (reported as error bars in Figure 7).

Figure 7 presents the experimental data fitted to the following polynomial function

$$
\lambda=a \mathbf{R H}+b \mathbf{R H}^{2}+c \mathbf{R H}^{3}
$$

with the parameters given in Table 1.

\begin{tabular}{cccc}
\hline$T=24^{\circ} \mathrm{C}$ & $a$ & $b$ & $c$ \\
\hline$\sigma=0$ & 0.135 & $-1.700 .10^{-3}$ & $1.218 .10^{-5}$ \\
\hline$\sigma=8.7 \pm 0.2 \mathrm{MPa}$ & 0.113 & $-0.959 .10^{-3}$ & $0.587 .10^{-5}$
\end{tabular}

Table 1. Coefficients of the polynomial functions used to fit the sorption isotherm data with and without applied stress.

As reported in the literature ${ }^{2}$, the acid form of Nafion ${ }^{\circledR}$ presents a sigmoidal shape composed of a concave part in the range $[0-65 \% \mathrm{RH}]$ and a convex part above $65 \% \mathrm{RH}$. The concave part is 
typically described by the Dual-Mode sorption model, which assumes that one population of water molecules is sorbed following a Henry-type dissolution mechanism while a second population, strongly bonded due to hydrogen interactions, resides in the hydration layer around the ionic groups (Langmuir population). The convex part of the isotherm is attributed to water molecules forming clusters at high relative humidity. This last population is responsible for most of the dimensional swelling of the membrane and its sorption kinetics is $\operatorname{slow}^{39,40}$ as it requires the structural rearrangement of the polymer chains ${ }^{41}$.

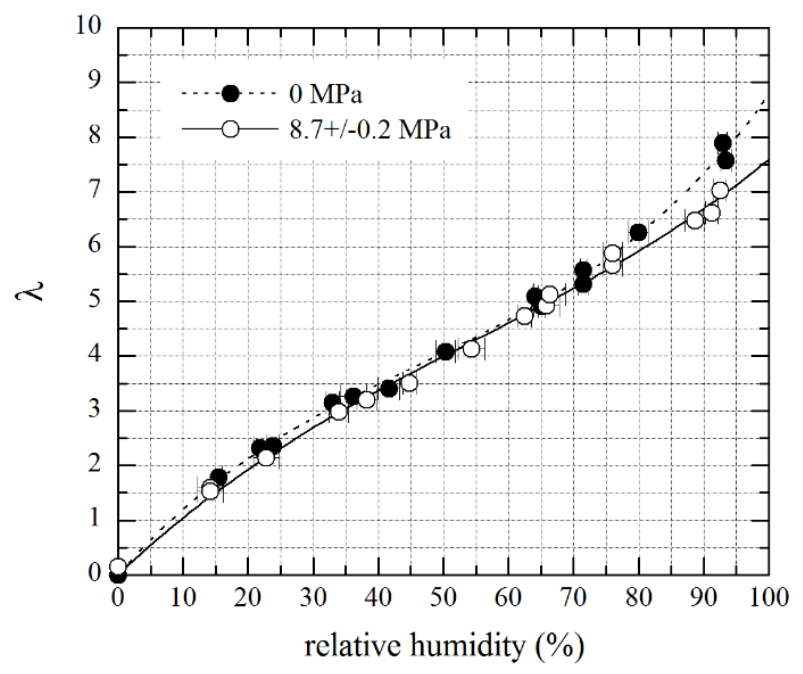

Figure 7. Influence of a compressive stress $(8.7 \mathrm{MPa})$ on water vapor sorption in Nafion ${ }^{\circledR} \mathrm{N} 1110$ at $24^{\circ} \mathrm{C}$.

The comparison of the two sorption curves revealed that the imposed stress impacts the sorption isotherm markedly at high relative humidity (above $\sim 70 \% \mathrm{RH}$ ). On the contrary, the data measured with and without stress were nearly identical at low RH (given the experimental error bars) although they were systematically lower for the stressed membrane. The water loss was on the order of 5 to $12 \%$ between 75 and $\sim 95 \%$ RH and less than $4 \%$ below $70 \%$ RH. Based on these observations, we chose to focus the rest of our study on hygrometric conditions $\geq \mathbf{6 0} \% \mathrm{RH}$.

\section{Effects of compression on water uptake $(\lambda)$ and self-diffusion coefficient $\left(D_{s}\right)$}

Successive compression levels ranging from $0.7 \pm 0.2 \mathrm{MPa}$ to $11.1 \pm 0.2 \mathrm{MPa}$ were applied to a N1110 membrane vapor-equilibrated at $\mathbf{R H} \geq \mathbf{6 0} \%$ in order to study water loss as a function of 
stress. The data of Figure 8 represent the water content of the stressed membrane relatively to its value $\lambda^{*}$ measured at equilibrium at the same RH before the compression tests: the water content decreased progressively with the compressive stress for all the humidity conditions. As mentioned above, the data point out two different behaviors: at very high relative humidity $(\mathrm{RH}=95 \%$ and $98 \%$ ), where the membrane lost $5 \%$ to $15 \%$ of its water, and at lower relative humidity (RH from $61 \%$ to $85 \%$ ) where only $5 \%$ (at most) of the water was forced out of the membrane at the higher available stress. The trends are also very different: at low RH the water loss was progressive in the entire stress range while there seems to be two different regimes when the membrane was highly hydrated. In this case, water desorption was high in the range 0-3 MPa but followed more or less the same trend as at low RH above $3 \mathrm{MPa}$ (moderate water loss).

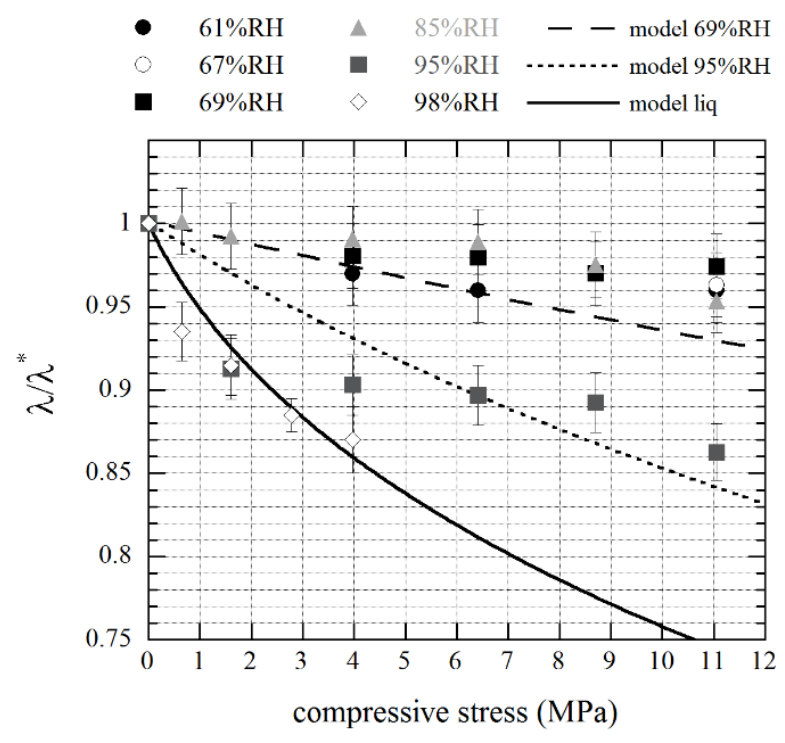

Figure 8. Effect of a variable compressive stress on the water content for different relative humidity.

The $\lambda$ values were normalized by $\lambda^{*}$, the water content of the membrane measured at equilibrium before compressing the membrane sample.

The lines on the figure represent the results of simulations of the effect of stress on the water content using the micro/macrohomogenization method adapted in Nafion ${ }^{\circledR}$ by Colinart et $a l .{ }^{25}$ in the $69 \% \mathrm{RH}$ and $95 \%$ cases. The simulations are compared to the case where the membrane is at equilibrium with liquid water. The model can reproduce the observed trends and the magnitude of 
the water loss but it fails to describe the initial steep decrease measured at low stress in the $95 \% \mathrm{RH}$ case. These results are discussed in more details in the Discussion section of the paper.

Figure 9 displays the water self-diffusion coefficient measured by PFGNMR at $24^{\circ} \mathrm{C}$ in Nafion® N1110 with and without applied stress as a function of the relative humidity. The coefficient was measured in the through-plane $(\boldsymbol{y})$ direction of the membrane sample. The reference (unstressed) values are in agreement with literature data ${ }^{27,42}$ and present a strong dependence on $\mathrm{RH}$, increasing from $5.68 .10^{-11} \mathrm{~m}^{2} / \mathrm{s}$ at $\mathrm{RH}=31 \%$ to $2 \cdot 37 \cdot \mathbf{1 0}^{-10} \mathrm{~m}^{2} / \mathbf{s}$ at $\mathrm{RH}=95 \%$. The dashed line on the figure corresponds to the empirical relation given by Equation 2 with $\boldsymbol{\alpha}=\mathbf{9 . 7 4 . 1 0 ^ { - 1 1 }}$.

$$
\mathrm{D}_{\mathrm{s}}\left[10^{-10} \mathrm{~m}^{2} / \mathrm{s}\right]=\alpha \frac{\mathrm{RH}}{100} \exp \left(\frac{\mathrm{RH}}{100}\right)
$$

Equation 2

When the $11 \mathrm{MPa}$ stress was applied, the water self-diffusion coefficient dropped significantly whatever the relative humidity. At $95 \% \mathrm{RH}$ it decreased from $2.37 .10^{-10} \mathrm{~m}^{2} / \mathrm{s}$ to $1.96 .10^{-10} \mathrm{~m}^{2} / \mathrm{s}$ when the stress was set to $11.1 \mathrm{MPa}\left(17.3 \%\right.$ drop) while it decreased from $1.11 .10^{-10} \mathrm{~m}^{2} / \mathrm{s}$ to $0.86 .10^{-10} \mathrm{~m}^{2} / \mathrm{s}$ at $61 \% \mathrm{RH}(23.5 \%$ drop). The fit to the data at $11 \mathrm{MPa}$, using Equation 2, gives $\alpha=7.92 \cdot 10^{-11} \mathrm{~m}^{2} / \mathrm{s}$.

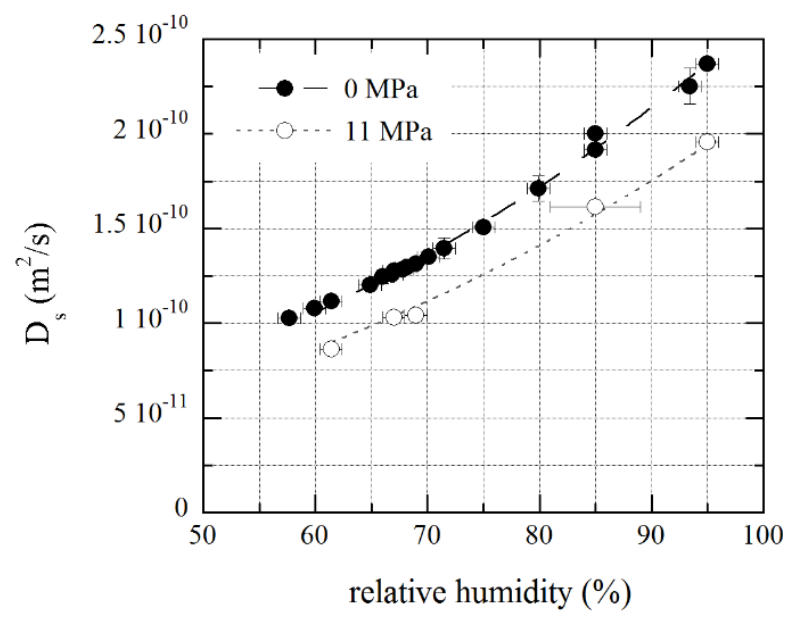

Figure 9. Influence of the compressive stress (11 MPa) on the water self-diffusion coefficient in Nafion ${ }^{\circledR}$ N1110 $\left(24^{\circ} \mathrm{C}\right)$. 
The coefficient $\mathbf{D}_{\mathbf{s}}$ was also measured in the two other orthogonal directions ( $\mathrm{x}$ and $\mathrm{z}$ ) to check the presence of any stress-induced diffusion anisotropy. The measurements were performed in four different humidity conditions as the applied stress was increased in the range $0 \mathrm{MPa}<\sigma<11.1$ MPa. As observed in Figure 10, the diffusion coefficient decreased in the membrane-plane directions in the same manner and in the same proportions as in the through-plane direction showing that diffusion remained isotropic (within the experimental uncertainties of our measurements) when a moderate stress was applied in the normal direction of the membrane. We note that the self-diffusion coefficient was seen isotropic in the unstressed membrane which is in apparent contradiction to the results reported before in extruded Nafion®. In this family of membranes the diffusion anisotropy ( 12 to $18 \%)$ comes from the small uniaxial in-plane order induced by the fabrication process and is aligned with the machine direction ${ }^{26,34,38}$. This effect is not measured in the present study because we did not align the machine direction with any measuring direction of the diffusion coefficient in the plane of the membrane samples.

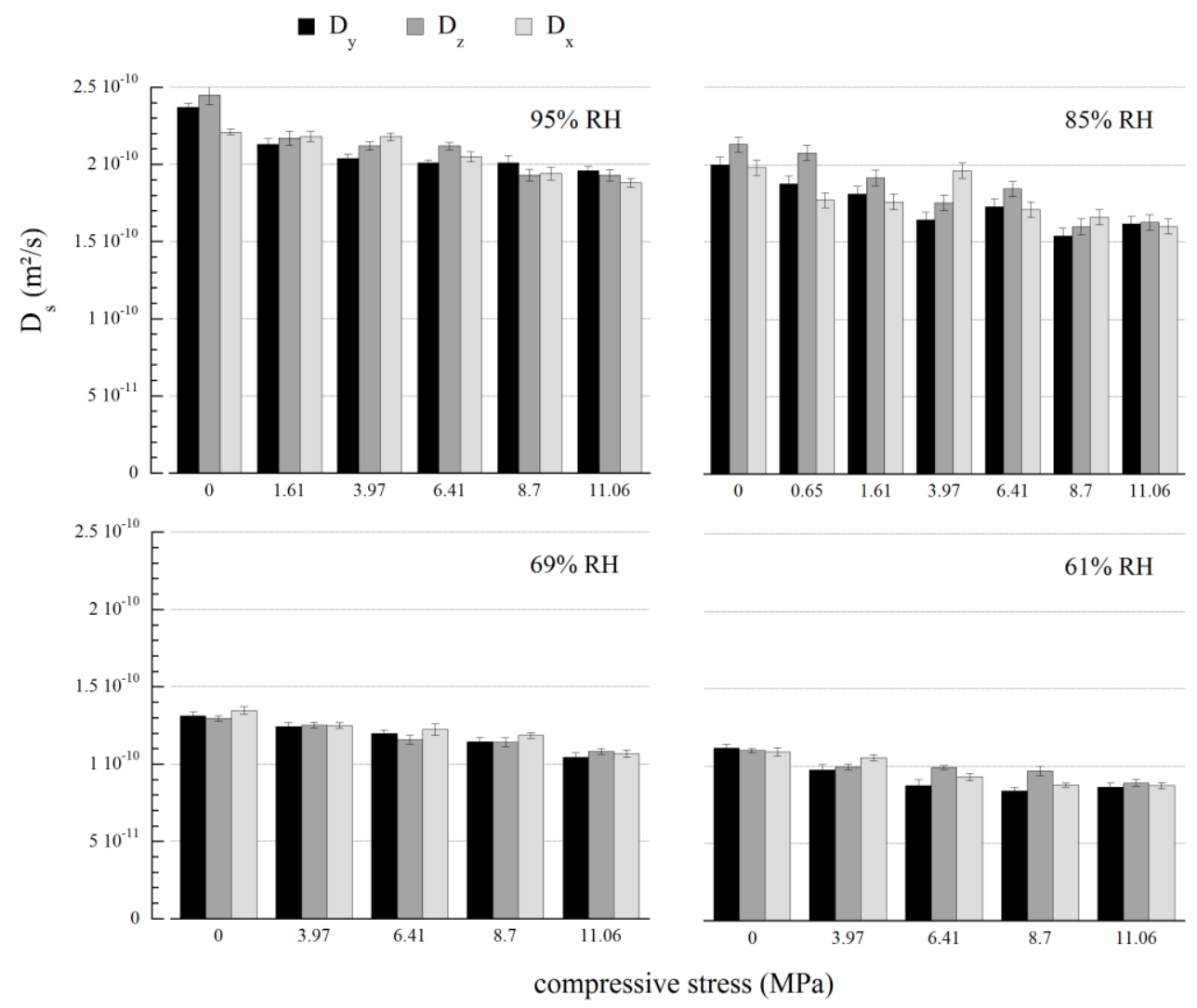


Figure 10. Water self-diffusion coefficient measured in Nafion ${ }^{\circledR}$ N1110 in the through-plane $(y)$ and in-plane ( $x, z)$ directions, as a function of the imposed stress. The measurements were performed at different RH.

\section{Evolution of $D_{\mathrm{s}}$ as a function of water content $\lambda$.}

The water self-diffusion coefficient measured in the through-plane direction is plotted as a function of the water uptake $\lambda$ in Figure 11. This representation allows the comparison of the results when the stressed and unstressed samples are hydrated at the same water content and thus separates the respective effects of hydration and compression on self-diffusion. The two curves are fitted using the phenomenological correlation of Equation $3^{27}$ with the parameters given in Table 2.

$$
D_{s}\left[\mathbf{m}^{2} / \mathbf{s}\right]=\beta \lambda[(1-\exp (-\gamma \lambda)] \quad \text { Equation } 3
$$

\begin{tabular}{ccc}
\hline$T=24^{\circ} C$ & $\beta$ & $\gamma$ \\
\hline$\sigma=0$ & $3.24 .10^{-11}$ & 0.278 \\
\hline$\sigma=11 M P a$ & $4.71 .10^{-11}$ & 0.117 \\
\hline
\end{tabular}

Table 2. Coefficients of the correlation (Equation 3) used to fit the diffusion curves with and without applied stress.

Figure 11 shows that the measured differences in the self-diffusion between the stressed and unstressed cases are only partly cancelled when the coefficient is plotted as a function of the water content. This is especially true at low water content: at high water content the water self-diffusion seems to follow the same tendency as in the unconstrained membrane.

The decrease of Ds is thus only partially due to a loss of water: other effects, such as a stressinduced modification of the microstructure, must be considered. Such modification, however, should be isotropic as it does not induce any measurable differences in the diffusion along the three orthogonal axes (Figure 10). 


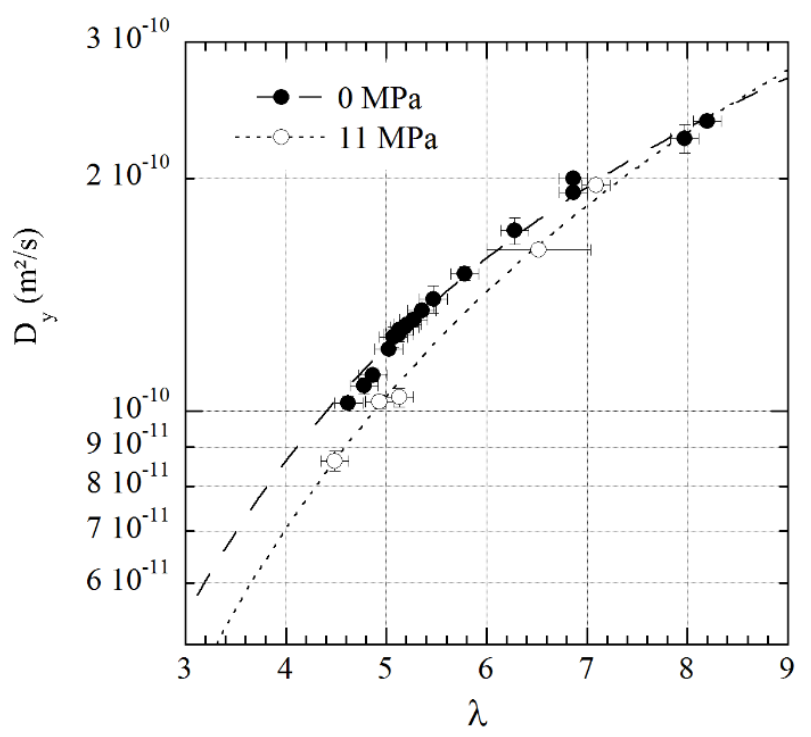

Figure 11. Water self-diffusion through-plane $D_{y}$ versus water content $\lambda$ in membrane at $24^{\circ} \mathrm{C}$.

\section{Return to initial state after suppression of the stress}

During the operation of the PEMFC, the electrolyte membrane undergoes multiple stress application and release cycles and therefore it is of interest to know if the changes observed in the water content and in the diffusion properties persist when the compressive stress disappears. In this purpose, $\lambda$ and $D_{s}$ were measured a few hours after the suppression of the compressive load. The diffusion data of membranes equilibrated at $69 \% \mathrm{RH}$ and $95 \% \mathrm{RH}$ are represented in Figure 12 to illustrate the behavior at high and "low" humidity.

Our results show that both the water content $\lambda$ and the diffusion coefficient returned back to their initial values before compression, whatever the RH conditions or the direction of measurement. We observed that the initial state was recovered after $\sim 2$ hours at $95 \% \mathrm{RH}$ while it took a much longer time (with a maximum of 8 hours) at lower $\mathrm{RH}(\mathrm{RH} \leq 85 \%)$ : the modifications imposed by compression on the membrane's structure need more time to relax and disappear at low RH. As discussed earlier, below $85 \% \mathrm{RH}$, these modifications impacted both the sorption and diffusion data whereas above $85 \% \mathrm{RH}$, the decrease of the diffusion coefficient was mostly due to a loss a water. 

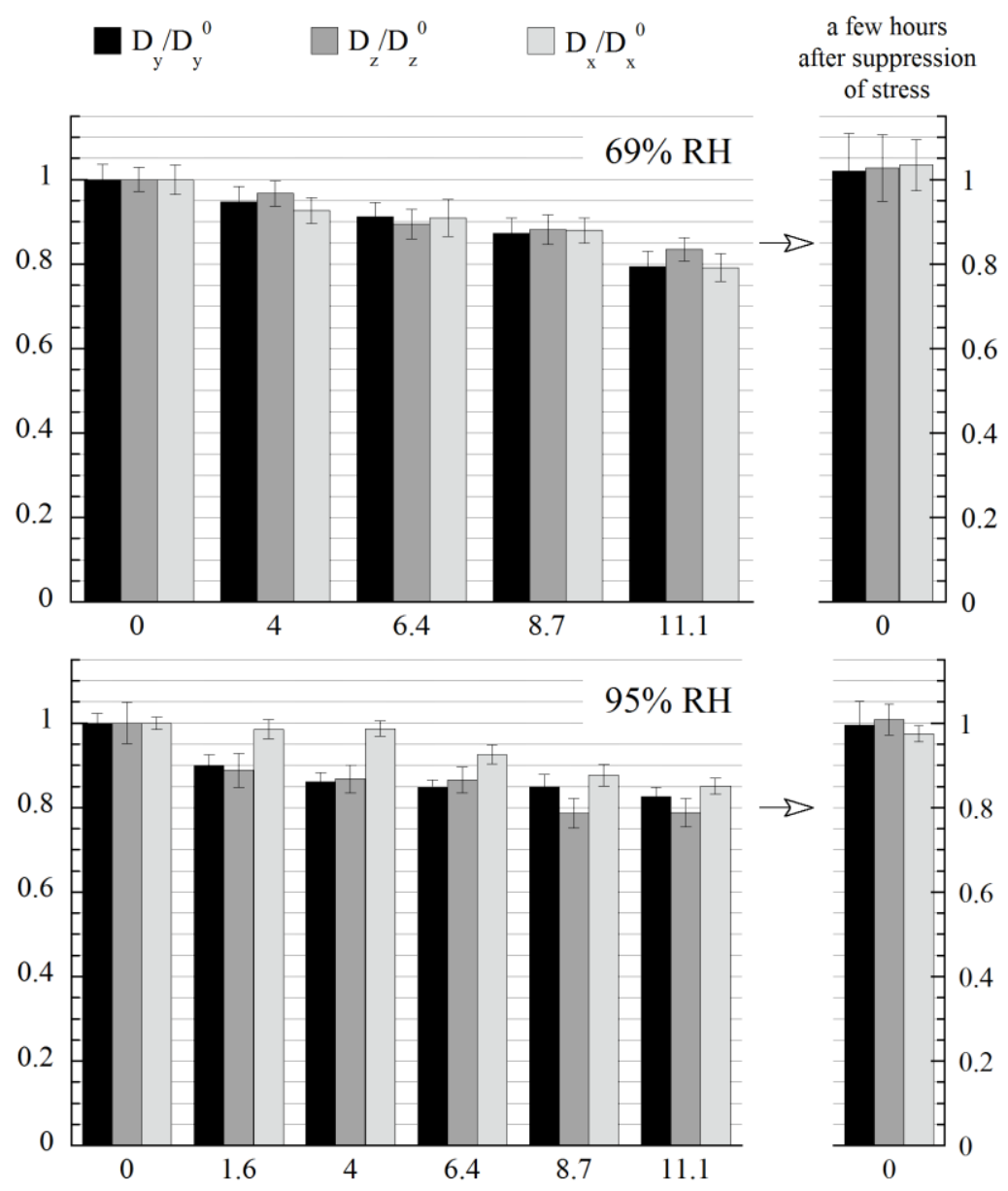

compressive stress $(\mathrm{MPa})$

Figure 12. Water self-diffusion coefficient measured at $69 \% \mathrm{RH}$ and $95 \% \mathrm{RH}$ as a function of applied stress and several hours after suppression of the compression pressure. The values are normalized by $D^{0}$, the coefficient measured at 0 MPa before the test.

\section{Discussion}

\section{Impact of compression stress on water content}

The present study aims at evaluating the effects of a compressive stress on the water content and its dynamical properties in weakly charged polymers such as Nafion®. Our results demonstrated that the application of a moderate stress $[0-11 \mathrm{MPa}]$ normal to the membrane plane causes some of the water to leave the structure of the polymer. The order of magnitude of this compression stress is consistent with the clamping pressure to which membrane-electrodes assemblies are subjected in 
fuel cell stacks. The water loss was marked with a sample initially equilibrated at high relative humidity ( $15 \%$ water loss at RH $>85 \%$ and a stress of $11 \mathrm{MPa})$ and very moderate (a few percent) at lower $\mathrm{RH}$. At high $\mathrm{RH}$, most of the water loss happened at low stress $(<3 \mathrm{MPa})$ and then followed the same trend as at low RH. These observations can be understood considering the reduction of the Young modulus with hydration ${ }^{43,44}$ due to the plasticization of the polymer by water molecules. In the high hydration zone, the membrane is less rigid and a small stress can influence the water content. Furthermore, when the membrane is highly hydrated $(\mathrm{RH}>85 \%$, or in liquid water) the water phase is continuous ${ }^{41}$, the dimensional swelling of the membrane is the highest ${ }^{42}$ and the water molecules are less strongly bound to the polymer matrix ${ }^{18,20}$. The membrane rigidity, the dimensional swelling and the interactions between water molecules and the matrix are the factors that control the water content of the membrane. Their relative values at very high $\mathrm{RH}$ explain why a relatively small compression load $(<3 \mathrm{MPa})$ can efficiently push water out of the polymeric structure by reduction of the membrane volume. Our results are in agreement with the early work of Fontanella et al. ${ }^{45}$ who studied the evolution of the electrical conductivity and longitudinal ${ }^{1} \mathrm{H}$ NMR relaxation time as a function of the applied pressure. The authors showed that, at low hydration, the decrease of both parameters with pressure were in agreement with the fact that, in this range of hydration, the molecular water motion is determined by the host matrix. At high water content, on the contrary, the observed behavior approached the one seen in liquid water such that the transport is controlled by the aqueous component. The framework of the mechanical model developed by Colinart et al. ${ }^{25}$ can also be used to rationalize our observations. In this model, a micro/macro homogenization procedure is applied to the Nafion ${ }^{\circledR}$ membrane to compute and predict its swelling behavior under a compressive load. In case of a uniform compression, the total stress tensor $\sigma_{\mathrm{T}}$ balances the compressive stress $P^{25}$ :

$$
-P=\sigma_{\mathrm{T}}=\sigma_{\mathrm{el}}-p_{b}-\Pi_{S P}
$$

\section{Equation 4}


$\sigma_{\mathrm{el}}$ is the elastic stress tensor of the porous membrane. $p_{b}$ is the pore pressure: it equals the external liquid water pressure when the membrane is equilibrated with liquid water or it is evaluated by the Kelvin equation when the membrane is equilibrated with water vapor. $\Pi_{S P}$ is the swelling pressure and is defined as the sum of the osmotic pressure and the Maxwell tensor accounting for the electrostatic effect. As shown by Colinart et $a l^{25}{ }^{25}$ the electrostatic effects are on the order of $1 \mathrm{MPa}$ and are thus negligible compared to the osmotic term (>10 MPa in these conditions, see e. g. in reference ${ }^{46}$ ) which demonstrates that the swelling pressure within the pores can be considered equal to the osmotic pressure. The model can provide the respective values of the elastic and osmotic parts of the internal pressure when a compressive stress $\mathrm{P}$ is applied. Finally, the model can also give a fraction $F$ of the total external pressure $P_{\text {tot }}$ (i.e. the sum of the compressive stress and the pore pressure: $\boldsymbol{P}_{t o t}=\boldsymbol{P}-\boldsymbol{p}_{\boldsymbol{b}}$ ) balanced either by the swelling pressure or the compressive elastic strain, $F_{S P}$ and $F_{e l}$ respectively. Simulations are performed for liquid equilibrated membrane and for vapor equilibrated membrane at $69 \% \mathrm{RH}$ and $95 \% \mathrm{RH}$ by considering an elastic modulus of 100 MPa for the solid matrix, and a sulfonic charge density of $1200 \mathrm{~mol} / \mathrm{m}^{3}$. The numerical results for the normalized water content are presented in Figure 8 together with the measured data. The model shows that the water content is reduced by $25.5 \%$ in the membrane compressed at $11 \mathrm{MPa}$ in liquid water, which is in agreement with the experimental results of Budinski et al. ${ }^{46}$ and Kusoglu et al. ${ }^{10}$. In addition, as showed by $F_{S P}$ and $F_{e}$ as a function of the applied compressive stress $\mathrm{P}$ (Figure 13), $32 \%$ of the external pressure is balanced by the swelling pressure. Furthermore, as the compressive stress $P$ increases, the part of the strain balanced by the elastic pressure increases (see Figure 13). When the membrane is equilibrated with water vapor, the pore pressure is constant and highly negative (-7.16 $\mathrm{MPa}$ at $95 \% \mathrm{RH}$ and $-51 \mathrm{MPa}$ at $69 \% \mathrm{RH})$. Particularly at $69 \% \mathrm{RH}$, the pore pressure is dominant with respect to the applied pressure $P$, in the range of our experimental study. Therefore, the maximum compressive stress $P$ is thus too small to balance the internal pressure and very few water is removed from the sample, as shown by the experiments. Nevertheless, the sum of 
the compressive stress $P$ and the pore pressure should be balanced by the swelling pressure and elastic strain. Their fraction are also plotted in Figure 13 for the high and "low" RH cases. Whatever the RH level, the elastic pressure is always much higher than the osmotic pressure. Furthermore, the part of the strain balanced by the elastic pressure still increases slightly with increasing pressure at $95 \% \mathrm{RH}$, whereas it is almost constant at $69 \% \mathrm{RH}$. Finally, the model is able to capture the main features of the evolution of the water content, namely the highly non-linear shape and the order of magnitude of the water desorption. It illustrates the differences between the liquid case $(25.5 \%$ drop in the water content at $11 \mathrm{MPa})$, the high $\mathrm{RH}$ case (16\% drop at $95 \% \mathrm{RH})$ and the "low" RH case ( $7 \%$ drop at $69 \%$ RH). However, because the model considers the membrane as a purely elastic medium with linear swelling with respect to the water volume fraction, it fails to reproduce the observed initial fast decrease of water content with the mechanical stress.

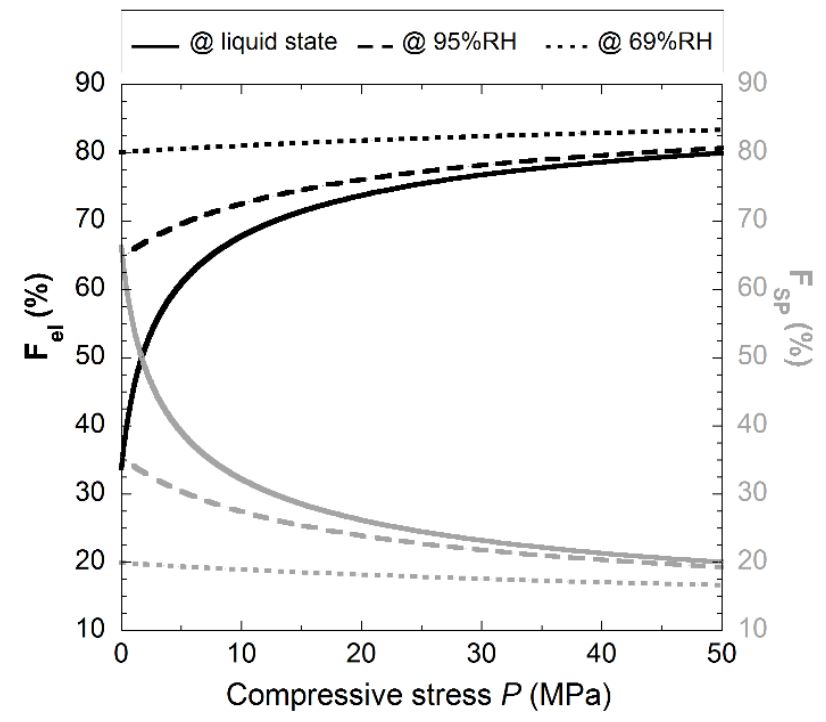

Figure 13. Fraction $F$ of the total external pressure $\boldsymbol{P}_{t o t}\left(\right.$ i.e. $\left.P-\boldsymbol{p}_{b}\right)$ balanced by the swelling pressure or the elastic strain, respectively $F_{S P}$ and $F_{e l}$, as function of compressive stress at $69 \% \mathrm{RH}, 95 \% \mathrm{RH}$ and in liquid water. 
Impact of compression on the water diffusion properties and link to the structure under compression

The PFGNMR measurements showed that compression has a large impact on the water diffusion properties of Nafion ${ }^{\circledR}$. We observed that the water self-diffusion coefficient decreases when the normal stress is applied and that this effect is relatively important whatever the RH condition, which is different from the observed effect on water content. The plot of Ds as a function of $\lambda$ Figure 11 demonstrates that this reduction in mobility is not entirely due to the loss of water but comes also from a modification of the internal structure under compression. The length scale associated to our self-diffusion measurement is on the order of a few microns, which means that the structural modifications must be effective at a smaller (or equal) scale. The results of Kusoglu et al. ${ }^{12}$ can be evoked at this stage to complement our observations. The authors have performed a SAXS study of the deformed structure of custom made $750 \mu$ m-thick Nafion ${ }^{\circledR}$ under compression in liquid water. In the face-on (in-plane) configuration, they measured a shift of the ionomer peak to the low diffusion angles which indicates that the spacing between the water channels increases in the plane of the membrane when the stress is applied. In the edge-on (thickness) direction, they measured a shift to the higher angles which indicates a decrease of the mean distance between the water channels. For vapor-equilibrated membranes $(100 \%$ and $94 \% \mathrm{RH})$ the measurements show a similar increase on the mean spacing in the plane of the membrane; however, the effects are much less pronounced. No result concerning the evolution of the spacing in the thickness direction was reported for vapor-equilibrated samples. This study and our measurements demonstrate that the modifications made on the nanostructure by compression (as seen by SAXS) have an impact on the water mobility at the micron scale (as seen by PFGNMR). Another way of characterizing the modification of the local polymer structure could be done by measuring the relation between the ${ }^{1} \mathrm{H}-\mathrm{NMR}$ chemical shift and the water content in the unstressed and stressed samples (see Figure S.I.4 of the Supporting Information). Although the scattering of the points makes it difficult to fit 
the data accurately, the figure shows that the functional form $(\Delta \delta \propto 1 / \lambda)$ is the same in both cases but that the proportionality coefficient differs. As the ${ }^{1} \mathrm{H}$ chemical shift is sensitive to the local structure in the vicinity of the probed protons (and in particular the isotropy of the environment) this finding could outline the structure modification at the immediate neighborhood of the water molecule (molecular scale).More data would be necessary however in order to prove this claim.

The water self-diffusion is usually analyzed by invoking the tortuosity of the water transport medium. Based on the structural model proposed by Schmidt-Rohr and Chen ${ }^{47}$ self-diffusion occurs through the water channels, i.e. the water-filled transport pathways of the polymeric structure. Our set of results shows that compression impacts not only the water diffusivity by changing the structure at the nanoscale but also the transport channel connectivity i.e. the tortuosity of the transport pathways. The effect of compression on water transport is thus seen here as a slowing down of self-diffusion due to both the modification of the local structure at the scale of a water channel and at the micron scale. The data of Figure 10 show that this effect is isotropic as no marked difference is measured between the diffusion coefficient in the directions of the plane and in the thickness direction of the stressed membrane. The different behaviors observed in the nanostructure between the in-plane and the through-plane directions in the liquid-equilibrated Nafion ${ }^{\circledR}{ }^{12}$ are thus not reflected here in the dynamical behavior of the adsorbed water. One possible reason is that the anisotropic effects are too small to be detected within the precision of our measurements. Another explanation resides in the application conditions of the compressive force. Because the membrane is thin and because the surface of the porous quartz discs (see Figure 1 in the experimental section) is rough, the applied stress is probably close to a uniform compression rather than a purely uniaxial compression. The strain in the membrane plane is probably hindered by the friction between the membrane surfaces and the quartz so that the membrane deformation is nearly isotropic. 


\section{Possible impact of compression on proton conductivity}

The impact of the reduction of water mobility on the membrane performance in the PEMFC is thought to be significant as water diffusion represents an indicator of the efficiency of the proton transfer through the membrane structure. Our results represent a fairly reliable indication towards the decrease of the membrane conductivity along the three axes of the membrane when a compressive stress is applied. In the literature few experimental data have been published on the effect of compression on the proton conductivity of Nafion ${ }^{\circledR}$. Ma et al. ${ }^{48}$ measured a very high conductivity anisotropy between the in-plane and thickness directions of N117 in sample pre-treated under compression at high temperature $\left[>60 \mathrm{MPa}\right.$ at $\left.150^{\circ} \mathrm{C}\right]$. This result is easily explained considering that the structure is known to become highly oriented when a stress is applied at high temperature. The studies performed in membranes that were deformed under tensile stress at high temperature showed indeed that high water diffusion and proton conductivity anisotropies are induced by the aligned structure and that these modifications are permanent when the stress is removed ${ }^{34,38,49}$. The study of Yun et al. ${ }^{16}$ and Kusoglu et al. ${ }^{12}$ were performed under compression in non pre-treated samples i.e. closer to the conditions of the present study. The former authors designed a 2-electrodes impedance cell in order to perform electrochemical impedance spectroscopy (EIS) in the through-plane direction as well as measure the corresponding membrane thickness. An equivalent circuit model was used to separate the through-plane membrane resistance, the interfacial contact resistance between the electrodes and the membrane surface and the electronic cell resistance from the total high frequency resistance. The analysis in N115 and N117 showed that the contact resistance decreased with the increasing pressure and that, conversely, the membrane resistance increased in such a way that the total high frequency resistance did not vary much with compression. In N112, the total resistance decreased markedly with pressure, mostly due to a decrease of the contact resistance but also to the increase of the membrane resistance. As a result, the calculated proton conductivity in the normal direction was reported to be strongly 
reduced by the applied stress (by a factor 3 to 7) when the membrane was compressed (the maximum stress was $\sim 2.5 \mathrm{MPa}$ ). In the study of Kusoglu et al. the proton conductivity was measured in NR212 at low (50\%) and high (95\%) RH at different temperatures and for a compressive load of $\sim 8 \mathrm{MPa}$ at maximum. The authors reported that the effects of compression were negligible as no marked effect was observed as a function of the applied stress but they discussed a model that took into account the decrease of both the water content and the mean distance between the water channels in the membrane under stress. The model predicted a decrease of the conductivity in the plane with increasing stress with more pronounced effects at high $\mathrm{RH}$, which is in good agreement with our results on water content and self-diffusion variations.

The literature studies underline the fact that the EIS measurement of proton conductivity under compression remains a challenge as it faces experimental problems related, in particular, to the uncontrolled interfacial electronic resistances between the cell electrodes and the membrane surface. The present study illustrates the advantages of the evaluation of the water self-diffusion in the study of the membrane transport properties. Although the link between water mobility and proton transfer is not always unambiguous and may be dependent on the hydration conditions and the temperature of the studied membrane, the determination of the water self-diffusion coefficient is well established, relatively easy to implement and is free of interfacial effects as it is a non-contact method. The present work proves that the study of self-diffusion brings relevant information for both the understanding of fundamental aspects such as the link between structure and transport in a stressed membrane but also on more applied problems such as the pressure dependence of the exchange membrane performance in a working PEMFC stack.

\section{Conclusion}

In the present work, the effects of compression on water sorption and diffusion have been studied in a Nafion ${ }^{\circledR}$ membrane equilibrated in water vapor. A NMR compatible compression cell has been developed to measure quantitatively the water content of a membrane subjected to a normal stress 
and to simultaneously determine the water self-diffusion coefficient in the three spatial orthogonal directions without having to deal with any interfacial effect. Our results show that the external applied force can balance the internal elastic pressure in the membrane equilibrated at high $\mathrm{RH}$ (> $90 \%$ ) and lead to a substantial decrease of its water content. This effect is observed at low stress in a range $[0-3 \mathrm{MPa}]$ that embraces the clamping pressure of the membrane-electrode-assembly in a working PEM fuel cell or electrolyser. At low RH, the elastic and osmotic pressures become very high in the membrane so that compression has little effects of the water content in the [0-85\% RH] range. The diffusion measurements show that the water mobility is also affected in the stressed membrane: stress-induced structural modifications or reorganizations are seen at the micrometric scale through the decrease of the water self-diffusion coefficient. These effects, although completely reversible, likely impact the performance of the PEM in terms of proton conductivity because of the tight link existing between water mobility and proton transport.

As irreversible modifications (physical and/or chemical aging) are observed when combined stresses are applied on PEM membranes (air humidity / mechanical stress / radical attacks) a perspective of this work can be considered by using of our compression cell and NMR setup to study the coupled effect of air humidity and applied pressure in cycled ageing conditions.

\section{Acknowledgments}

The authors would like to thank the Région Lorraine for funding. They thank D. Greuet, N. Azrak, P. L. Marande and the machine shop of LEMTA (J.-Y. Morel, C. Gigant) for the design and the machining of the compression cell.

\section{Supporting Information}

The SI contain details about the calibration of the applied normal stress as a function of the pressure of the gas as well as the validation of our setup for the PFGNMR measurements. Examples of diffusion data measured on compressed membranes and the evolution of the chemical shift with the water content in the compressed N1110 are also given. 


\section{References}

(1) Chen, C.; Fuller, T. F. The effect of humidity on the degradation of Nafion ${ }^{\circledR}$ membrane. Polymer Degradation and Stability 2009, 94, (9), 1436-1447.

(2) Bas, C.; Flandin, L.; Danerol, A. S.; Claude, E.; Rossinot, E.; Alberola, N. D. Changes in the chemical structure and properties of a perfluorosulfonated acid membrane induced by fuel-cell operation. Journal of Applied Polymer Science 2010, 117, (4), 2121-2132.

(3) Healy, J.; Hayden, C.; Xie, T.; Olson, K.; Waldo, R.; Brundage, M.; Gasteiger, H.; Abbott, J. Aspects of the Chemical Degradation of PFSA Ionomers used in PEM Fuel Cells. Fuel Cells 2005, 5, (2), 302-308.

(4) Rodgers, M. P.; Bonville, L. J.; Kunz, H. R.; Slattery, D. K.; Fenton, J. M. Fuel Cell Perfluorinated Sulfonic Acid Membrane Degradation Correlating Accelerated Stress Testing and Lifetime. Chemical Reviews 2012, 112, (11), 6075-6103.

(5) De Moor, G. Approche multi-échelle des mécanismes de vieillissement des coeurs de pile à combustible. Grenoble Alpes, 2015.

(6) Mench, M. M.; Kumbur, E. C.; Veziroglu, T. N., Polymer Electrolyte Fuel Cell Degradation. In Polymer Electrolyte Fuel Cell Degradation, Kumbur, E. C.; Veziroglu, T. N., Eds. Academic Press: Boston, 2012; p iii.

(7) Lee, W.-k.; Ho, C.-H.; Van Zee, J. W.; Murthy, M. The effects of compression and gas diffusion layers on the performance of a PEM fuel cell. Journal of Power Sources 1999, 84, (1), 45-51.

(8) Ge, J.; Higier, A.; Liu, H. Effect of gas diffusion layer compression on PEM fuel cell performance. Journal of Power Sources 2006, 159, (2), 922-927.

(9) Mason, T. J.; Millichamp, J.; Neville, T. P.; El-kharouf, A.; Pollet, B. G.; Brett, D. J. L. Effect of clamping pressure on ohmic resistance and compression of gas diffusion layers for polymer electrolyte fuel cells. Journal of Power Sources 2012, 219, 52-59.

(10) Kusoglu, A.; Kienitz, B. L.; Weber, A. Z. Understanding the Effects of Compression and Constraints on Water Uptake of Fuel-Cell Membranes. Journal of The Electrochemical Society 2011, 158, (12), B1504-B1514.

(11) Spernjak, D.; Mukherjee, P. P.; Mukundan, R.; Davey, J.; Hussey, D. S.; Jacobson, D.; Borup, R. L. Measurement of Water Content in Polymer Electrolyte Membranes Using High Resolution Neutron Imaging. ECS Transactions 2010, 33, (1), 1451-1456.

(12) Kusoglu, A.; Hexemer, A.; Jiang, R.; Gittleman, C. S.; Weber, A. Z. Effect of compression on PFSA-ionomer morphology and predicted conductivity changes. Journal of Membrane Science 2012, 421-422, 283-291.

(13) Otmani, N. Détermination des contraintes mécaniques dans les membranes Nafion(r) au cours du fonctionnement en pile à combustible. Grenoble, INPG, 2009.

(14) Sutor, A. K.; Huguet, P.; Morin, A.; Gebel, G.; Le, T. S.; Deabate, S. Influence of Compressive Stress on the Water Content of Perfluorosulphonated Membranes: A $\mu$-Raman Study. Fuel Cells 2012, 12, (2), 162-168. 
(15) Budinski, M. K.; Cook, A. Osmotic Pressure of Water in Nafion®. Tsinghua Science \& Technology 2010, 15, (4), 385-390.

(16) Yun, S.-H.; Shin, S.-H.; Lee, J.-Y.; Seo, S.-J.; Oh, S.-H.; Choi, Y.-W.; Moon, S.-H. Effect of pressure on through-plane proton conductivity of polymer electrolyte membranes. Journal of Membrane Science 2012, 417-418, 210-216.

(17) Rubatat, L.; Gebel, G.; Diat, O. Fibrillar Structure of Nafion: Matching Fourier and Real Space Studies of Corresponding Films and Solutions. Macromolecules 2004, 37, (20), 7772-7783.

(18) Kawano, Y.; Wang, Y.; Palmer, R. A.; Aubuchon, S. R. Stress-Strain Curves of Nafion Membranes in Acid and Salt Forms. Polímeros 2002, 12, 96-101.

(19) Choi, P.; Datta, R. Sorption in Proton-Exchange Membranes: An Explanation of Schroeder's Paradox. Journal of The Electrochemical Society 2003, 150, (12), E601-E607.

(20) Bauer, F.; Denneler, S.; Willert-Porada, M. Influence of temperature and humidity on the mechanical properties of Nafion ${ }^{\circledR} 117$ polymer electrolyte membrane. Journal of Polymer Science Part B: Polymer Physics 2005, 43, (7), 786-795.

(21) Nazarov, I.; Promislow, K. The Impact of Membrane Constraint on PEM Fuel Cell Water Management. Journal of The Electrochemical Society 2007, 154, (7), B623-B630.

(22) Freger, V. Elastic energy in microscopically phase-separated swollen polymer networks. Polymer 2002, 43, (1), 71-76.

(23) Kusoglu, A.; Santare, M. H.; Karlsson, A. M.; Cleghorn, S.; Johnson, W. B. Micromechanics model based on the nanostructure of PFSA membranes. Journal of Polymer Science Part B: Polymer Physics 2008, 46, (22), 2404-2417.

(24) Eikerling, M. H.; Berg, P. Poroelectroelastic theory of water sorption and swelling in polymer electrolyte membranes. Soft Matter 2011, 7, (13), 5976-5990.

(25) Colinart, T.; Perrin, J. C.; Moyne, C. Application of a Micro/Macro-homogenization Procedure to the Investigation of the Mechanical Behavior of Ionomer Membranes for Fuel Cells. Journal of Polymer Science Part B-Polymer Physics 2014, 52, (22), 1496-1509.

(26) Klein, M.; Perrin, J.-C.; Leclerc, S.; Guendouz, L.; Dillet, J.; Lottin, O. Anisotropy of Water Self-Diffusion in a Nafion Membrane under Traction. Macromolecules 2013, 46, (23), 9259-9269.

(27) Maldonado, L.; Perrin, J. C.; Dillet, J.; Lottin, O. Characterization of polymer electrolyte Nafion membranes: Influence of temperature, heat treatment and drying protocol on sorption and transport properties. Journal of Membrane Science 2012, 389, 43-56.

(28) MacMillan, B.; Sharp, A.; Armstrong, R. An n.m.r. investigation of the dynamical characteristics of water absorbed in Nafion. Polymer 1999, 40, (10), 2471-2480.

(29) Blümich, B., NMR Imaging of Materials. Oxford university press: 2000.

(30) Ouriadov, A. V.; MacGregor, R. P.; Balcom, B. J. Thin film MRI - High resolution depth imaging with a local surface coil and spin echo SPI. J. Magn. Reson. 2004, 169, (1), 174-186. 
(31) Zhang, Z.; Marble, A. E.; MacMillan, B.; Promislow, K.; Martin, J.; Wang, H.; Balcom, B. J. Spatial and temporal mapping of water content across Nafion membranes under wetting and drying conditions. J. Magn. Reson. 2008, 194, (2), 245-253.

(32) Klein, M.; Perrin, J. C.; Leclerc, S.; Guendouz, L.; Dillet, J.; Lottin, O., Spatially and Temporally Resolved Measurement of Water Distribution in Nafion Using NMR Imaging. In Polymer Electrolyte Fuel Cells 13, Gasteiger, H. A.; Weber, A.; Shinohara, K.; Uchida, H.; Mitsushima, S.; Schmidt, T. J.; Narayanan, S. R.; Ramani, V.; Fuller, T.; Edmundson, M.; Strasser, P.; Mantz, R.; Fenton, J.; Buchi, F. N.; Hansen, D. C.; Jones, D. L.; Coutanceau, C.; SwiderLyons, K.; Perry, K. A., Eds. 2013; Vol. 58, pp 283-289.

(33) Perrin, J. C.; Klein, M.; Leclerc, S.; Guendouz, L.; Dillet, J.; Lottin, O., NMR Investigation of Water Diffusion in a Nafion (R) Membrane Under Traction. In Polymer Electrolyte Fuel Cells 13, Gasteiger, H. A.; Weber, A.; Shinohara, K.; Uchida, H.; Mitsushima, S.; Schmidt, T. J.; Narayanan, S. R.; Ramani, V.; Fuller, T.; Edmundson, M.; Strasser, P.; Mantz, R.; Fenton, J.; Buchi, F. N.; Hansen, D. C.; Jones, D. L.; Coutanceau, C.; SwiderLyons, K.; Perry, K. A., Eds. 2013; Vol. 58, pp 781-788.

(34) Klein, M.; Perrin, J. C.; Leclerc, S.; Guendouz, L.; Dillet, J.; Lottin, O. NMR study of the anisotropic transport properties of uniaxially stretched membranes for fuel cells. diffusionfundamentals.org 2013, 18, (7), 1-4.

(35) Dubau, L.; Castanheira, L.; Maillard, F.; Chatenet, M.; Lottin, O.; Maranzana, G.; Dillet, J.; Lamibrac, A.; Perrin, J.-C.; Moukheiber, E.; ElKaddouri, A.; De Moor, G.; Bas, C.; Flandin, L.; Caqué, N. A review of PEM fuel cell durability: materials degradation, local heterogeneities of aging and possible mitigation strategies. Wiley Interdisciplinary Reviews: Energy and Environment 2014, 3, (6), 540-560.

(36) Huang, X.; Solasi, R.; Zou, Y.; Feshler, M.; Reifsnider, K.; Condit, D.; Burlatsky, S.; Madden, T. Mechanical endurance of polymer electrolyte membrane and PEM fuel cell durability. Journal of Polymer Science Part B: Polymer Physics 2006, 44, (16), 2346-2357.

(37) Levitt, M. H., Spin Dynamics: Basics of Nuclear Magnetic Resonance. Second ed.; Wiley: 2008 .

(38) Li, J.; Wilmsmeyer, K. G.; Madsen, L. A. Anisotropic diffusion and morphology in perfluorosulfonate ionomers investigated by NMR. Macromolecules 2009, 42, (1), 255-262.

(39) Hallinan, D. T.; Elabd, Y. A. Diffusion of Water in Nafion Using Time-Resolved Fourier Transform Infrared-Attenuated Total Reflectance Spectroscopy. The Journal of Physical Chemistry B 2009, 113, (13), 4257-4266.

(40) Kim, M.-H.; Glinka, C. J.; Grot, S. A.; Grot, W. G. SANS Study of the Effects of Water Vapor Sorption on the Nanoscale Structure of Perfluorinated Sulfonic Acid (NAFION) Membranes. Macromolecules 2006, 39, (14), 4775-4787.

(41) Kong, X.; Schmidt-Rohr, K. Water-polymer interfacial area in Nafion: Comparison with structural models. Polymer 2011, 52, (9), 1971-1974.

(42) Zhao, Q.; Majsztrik, P.; Benziger, J. Diffusion and interfacial transport of water in Nafion. $J$. Phys. Chem. B 2011, 115, (12), 2717-2727. 
(43) Satterfield, M. B.; Majsztrik, P. W.; Ota, H.; Benziger, J. B.; Bocarsly, A. B. Mechanical properties of Nafion and titania/Nafion composite membranes for polymer electrolyte membrane fuel cells. Journal of Polymer Science Part B: Polymer Physics 2006, 44, (16), 2327-2345.

(44) Satterfield, M. B.; Benziger, J. B. Viscoelastic properties of nafion at elevated temperature and humidity. J. Polym. Sci., Part B: Polym. Phys. 2009, 47, (1), 11-24.

(45) Fontanella, J. J.; Edmondson, C. A.; Wintersgill, M. C.; Wu, Y.; Greenbaum, S. G. HighPressure Electrical Conductivity and NMR Studies in Variable Equivalent Weight NAFION Membranes. Macromolecules 1996, 29, (14), 4944-4951.

(46) Budinski, M. K.; Cook, A. Osmotic pressure of water in Nafion. Tsinghua Science \& Technology 2010, 15, 385-390.

(47) Schmidt-Rohr, K.; Chen, Q. Parallel cylindrical water nanochannels in Nafion fuel-cell membranes. Nat Mater 2008, 7, (1), 75-83.

(48) Ma, S.; Siroma, Z.; Tanaka, H. Anisotropic conductivity over in-plane and thickness directions in Nafion-117. Journal of the Electrochemical Society 2006, 153, (12), A2274-A2281.

(49) Li, J.; Park, J. K.; Moore, R. B.; Madsen, L. A. Linear coupling of alignment with transport in a polymer electrolyte membrane. Nat. Mater. 2011, 10, (7), 507-511. 


\section{IMPACT OF A COMPRESSIVE STRESS ON WATER SORPTION AND DIFFUSION IN IONOMER MEMBRANES FOR FUEL CELLS. \\ A ${ }^{1}$ H-NMR STUDY IN VAPOR-EQUILIBRATED NAFION®.}

Assma El Kaddouri ${ }^{1,2,}{ }^{*}$, Jean-Christophe Perrin ${ }^{1,2}$, Thibaut Colinart ${ }^{3}$, Christian Moyne ${ }^{1,2}$, Sébastien Leclerc $^{1,2}$, Laouès Guendouz ${ }^{4}$, Olivier Lottin ${ }^{1,2}$

${ }^{1}$ Université de Lorraine, LEMTA, UMR 7563, Vandœuvre-lès-Nancy, F-54500, France

${ }^{2}$ CNRS, LEMTA, UMR 7563, Vandouvre-lès-Nancy, F-54500, France

${ }^{3}$ Univ. Bretagne Sud, FRE CNRS 3744, IRDL, F-56100 Lorient, France

${ }^{4}$ Institut Jean-Lamour, UMR 7198, CNRS, Université de Lorraine, Vandouvre-lès-Nancy, F- 54500, France

\section{For Table of Contents use only}

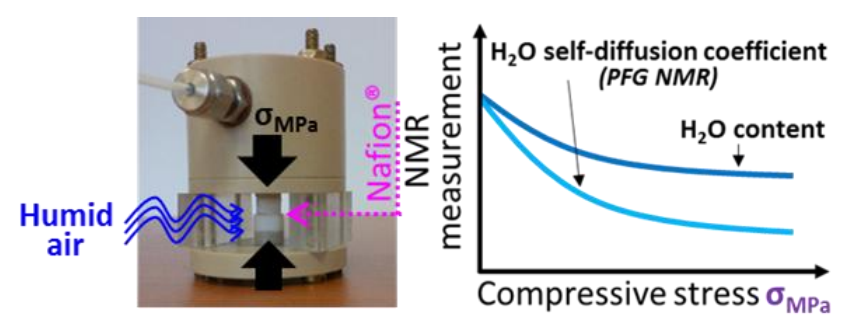

* corresponding author 
